\title{
Studies on Polyphenols Isolated from Branches of Prunus spinosa L. Species
}

\author{
OANA T. CIUPERCA ${ }^{1,2}$, CARMEN E. TEBRENCU2,3, ELENA IONESCU2,3, ELENA IACOB ${ }^{2}$, IRINA VOLF'* \\ ${ }^{1}$ Gheorghe Asachi Technical University, Faculty of Chemical Engineering and Environmental Protection, 73 Dimitrie \\ Mangeron Blvd., 700050, lasi, Romania \\ ${ }^{2}$ Research and Processing Centre for Medicinal Plants PLANTAVOREL S.A., 46 Cuza Voda, 610019, Piatra Neamt, Romania \\ ${ }^{3}$ Academy of Romanian Scientists, 54 Splaiul Independentei, 050094, Bucharest, Romania
}

\begin{abstract}
The aim of this study was to investigate the crude extracts isolated from branches of Prunus spinosa $L$. (Rosaceae), in order to quantify polyphenols and tannins using instrumental methods (UV-Vis spectrometry and HPTLC densitometry). The qualitative analysis on biomass revealed the presence of valuable compounds such as polyphenols, flavonoids and tannins. HPTLC fingerprinting of crude methanol extract showed several peaks, with different $R f$ values, corresponding to phytocompounds such as chlorogenic acid (Rf 0.52), neochlorogenic acid (Rf 0.58), caffeic acid ( $R f 0.95$ ) and protocatechuic acid (Rf 0.96). The quantitative analysis revealed that the branches of $P$. spinosa contain polyphenols $(2.97 \pm 0.059 \% \mathrm{~g}$ gallic acid equivalent) $g$ dried vegetal material) and tannins (0.90 $0.033 \% g$ tannic acid equivalent/g dried vegetal material). The HPTLC densitometry analysis offers information about the amount of neochlorogenic acid in the vegetal material $0.12 \% \mathrm{~g} / \mathrm{g}$. The content in polyphenols and tannins suggests the possibilities to use this species to separate compounds with antioxidant potential. These results open perspectives for complex valorization of Prunus spinosa species, a bioresource known only for phytotherapeutical and nutritional potential of their fruits.
\end{abstract}

Keywords: blackthorn, polyphenols, phytochemical identification, HPTLC, UV-Vis ,FTIR spectroscopy

Polyphenols are secondary metabolites synthesized in all parts of plants: bark, leaves, stem, root, flower, fruits and seeds. Each matrix has a different polyphenol composition and concentration [1,2]. Prunus spinosa L. (blackthorn or sloe), which belongs to the rose family (Rosaceae) is a shrub widespread in the temperate regions. Different flavonoids have been isolated from the leaves of $P$. spinosa such as kaempferol, quercetin, their $3-0-\alpha-L-$ arabinofuranosides, kaempferol 3- and 7-0- $\alpha-\mathrm{L}$ rhamnopyranosides [3]. The blackthorn constituents, such as flavonoid pentosides (arabinosides, xylosides, rhamnosides) and A-type procyanidin dimers with twicebonded structures are quite rare in nature [4]. This unique composition suggests a distinctive profile of $P$. spinosa. The number of studies investigating the phytotherapeutical potential of branches of $P$. spinosa has grown in recent years, but there are still limited. Special attention has been given to the antioxidant activity of the extract from the branches, leaves and fruits, as one of the possible action mechanism of the blackthorn polyphenols [5, 6]. Thus, the chemical characterization of branches and bark is important for evaluating the entire potentiality of its use. This study was focused mainly on the bioactive compounds from branches of $P$. spinosa species, in order to highlight new sources of biomass containing valuable polyphenols. The aim of this study was to investigate the polyphenols composition of branches of $P$. spinosa in order to identify and quantify some bioactive compounds with antioxidant potential. The identification of the main constituents was done applying the phytochemical study and using High Performance Thin Layer Chromatography (HPTLC). To have a complete qualitative confirmation of polyphenolic and flavonoid composition the UV-Vis and FT-IR spectroscopy were used. The chemical compounds quantification was done using densitometry and UV-Vis spectroscopy.

\section{Experimental part}

Materials and methods

Plant material: Branches of $P$. spinosa were collected from a temperate continental climate area (Siret Valley, Bacau county, Romania), in September 2016. The biomass was dried in a well-ventilated room, in a single layer, protected from direct solar light. The dried branches were grounded using a laboratory mill Microton MB550 to particles with $0.8 \mathrm{~mm}$ medium size. The sample of $P$. spinosa (PS) was stored in a clean desiccator until were used for phytochemical study and HPTLC, UV-Vis, FT-IR evaluation. The weight loss during drying was measured with a infrared KERN MLS Thermobalance.

Samples preparation: $5 \mathrm{~g}$ of vegetal material (PS) were dispersed separately in $100 \mathrm{~mL}$ of different solvents such as: methanol, ethanol $30 \% \mathrm{v} / \mathrm{v}$, ethanol $50 \% \mathrm{v} / \mathrm{v}$, and ethanol $70 \% \mathrm{v} / \mathrm{v}$. A batch extraction was performed at room temperature $20-23^{\circ} \mathrm{C}$, for $24 \mathrm{~h}$. Then the extracts were filtered and used for phytochemical study. The obtained methanolic extract (PSMe) was used also for UV-Vis and HPTLC evaluation. $1 \mathrm{~g}$ of vegetal material (PS) as such was used for FT-IR investigation.

\section{Chemicals and Reagents}

All the standards were of analytical grade or pure and the following were used: chlorogenic acid (min. 95\% HPLC from Sigma-Aldrich, Switzerland), hyperoside (min. 97\% HPLC, from Sigma-Aldrich, Switzerland), caffeic acid ( $\mathrm{min}$. 95\% HPLC from Sigma-Aldrich, Switzerland), neochlorogenic acid (min. 98\% HPLC, from Sigma-Aldrich, Switzerland), ferulic acid (min. 99\% HPLC, from SigmaAldrich, Switzerland), rutin hydrate (min. 95\% HPLC from Sigma-Aldrich, Switzerland), quercetin (min. 95\% HPLC from Sigma-Aldrich, Switzerland), protocatechuic acid (analytical standard from Fluka, Switzerland), kaempherol 
(analytical standard from Fluka, Switzerland). All the reagents were of analytical grade or pure: ethyl acetate, min. 99.5\% (Sigma-Aldrich), formic acid p.a. (Merck Germany), acetic acid p.a. (99\%, Silal Trading, Romania), methanol p.a., min. 99.8\% (Chempur Poland), polyethylene glycol 400 (PEG 400) (Ph. Eur, Fluka, Sigma-Aldrich, Switerland), diphenylboric acid aminoethyl ester (min. 97\%, Fluka, Switzerland). HPTLC plates G60 F254, 200x100mm (Merck, Darmstadt, Germany) were used as stationary phase for HPTLC identification and HPTLC densitometric assay.

\section{Qualitative analysis}

Phytochemical study: Characterization of $P$. spinosa extracts for various phytochemical constituents was carried out using standard methods [7] as described in table 1.

UV-Vis and FT-IR characterization: Molecular absorption spectrophotometry in ultraviolet/visible light (UV/VIS) is an analytical method based on the property of an ion or molecular species to absorb at certain wavelengths the UV/VIS radiation. Spectroscopic analysis was performed as follows: UV-Vis absorption spectra of extract was recorded using a Cary 50 UV-Visible Varian spectrophotometer, in the wavelength range between $200-800 \mathrm{~nm}$. The Fourier transform infrared spectrophotometer Cary 630 FT-IR Agilent was used to obtain the FT-IR spectra for the dried vegetal material in order to establish functional groups of the main bioactive compounds in the sample. FT-IR spectrum was recorded in $400-4000 \mathrm{~cm}^{-1}$ range.

HPTLC identification and densitometric assay: HPTLC chromatographic study was done according to literature
[8-10] using the equipment CAMAG LINOMAT IV, TLC 3 Scanner and as software WINCATS Planar Chromatography Manager.

Reference solutions: S1 (chlorogenic acid, hyperoside, caffeic acid), S2 (neochlorogenic acid, ferulic acid), S3 (rutin, quercetin), S4 (protocatechuic acid) and S5 (kaempherol) were prepared with a concentration of 0.2 $\mathrm{mg} / \mathrm{mL}$ in methanol for each and stored at $4^{\circ} \mathrm{C}$ until use.

Chromatographic procedure: Methanolic extract $(13 \mu \mathrm{L}$ - PSMe) and aliquots ( $5 \mu \mathrm{L}$ - S1; $5 \mu \mathrm{L}$ - S2; $6 \mu \mathrm{L}$ - S3; $6 \mu \mathrm{L}$ S4; $7 \mu \mathrm{L}-\mathrm{S} 5$ ) of reference solutions were applied separately as bands (start position - $31 \mathrm{~mm}$ from left side and $10 \mathrm{~mm}$ from the bottom, distance between bands $-6 \mathrm{~mm}$, bandlength - $12 \mathrm{~mm}$, delivery speed - $8 \mu \mathrm{L} / \mathrm{s}$ ) to silica gel 60 F254 - precoated HPTLC plates, $20 \times 10 \mathrm{~cm}$, using Camag Linomat IV automatic sample applicator. For the samples, the plates were developed in a saturated verticaldeveloping chamber at room temperature $\left(20-22^{\circ} \mathrm{C}\right)$ for 30 min, using as mobile phase a mixture of ethyl acetate: formic acid: acetic acid: distilled water (20:2,2:2,2:5,4). The development distance was $7 \mathrm{~cm}$. After the developing, the plates were air dried at room temperature. A visualising agent was selected based upon the class of phytoconstituents found in the preliminary phytochemical screening tests. The visualising reagent helps in detection as well as confirmation of the identity of the phytoconstituents. A $1 \%$ diphenylboric acid 2-aminoethyl ester methanolic solution and a $5 \%$ polyethylene glycol 400 ethanolic solution were used for spraying the plate, for visualising of polyphenols and flavonoids in the extract, followed by heating it at a temperature of $100^{\circ} \mathrm{C}$ for 10 $\mathrm{min}$. The processing of the chromatogram was carried out

\begin{tabular}{|c|c|c|c|}
\hline Phytoconstituents & Test & Observation & \multirow{10}{*}{$\begin{array}{c}\text { Table } 1 \\
\text { PRELIMINARY } \\
\text { PHOTOCHEMICAL } \\
\text { TESTS FOR } \\
\text { PLANT EXTRACTS }\end{array}$} \\
\hline \multicolumn{3}{|c|}{ Phenols } & \\
\hline Folin-Ciocalteu Test & $\begin{array}{l}2 \mathrm{~mL} \text { extract }+0.5 \mathrm{~mL} \text { Folin-Ciocalteu reagent }+2 \mathrm{~mL} \\
20 \% \text { sodium carbonate }\end{array}$ & Blue coloration & \\
\hline Ferric chloride Test & $2 \mathrm{~mL}$ extract $+1 \mathrm{~mL} 3 \%$ ferric chloride & Olive-brown coloration & \\
\hline Arnow Test & $\begin{array}{l}2.5 \mathrm{~mL} \text { extract }+2.5 \mathrm{~mL} \text { hydrochloric acid } 0.5 \mathrm{~N}+2.5 \mathrm{~mL} \\
\text { Arnow reagent }+2.5 \mathrm{~mL} \text { sodium hyaroxide }\end{array}$ & Red-brick coloration & \\
\hline \multicolumn{3}{|c|}{ Tannins } & \\
\hline The ferric chloride reaction & $\begin{array}{l}\text { ImL extract }+2 m L \text { distilled water }+2-3 \text { drops } 1 \% \text { ferric } \\
\text { chloride }\end{array}$ & $\begin{array}{l}\text { Blue-black coloration - gallic } \\
\text { tannins } \\
\text { Green-black coloration - } \\
\text { condensed tannins }\end{array}$ & \\
\hline \multicolumn{3}{|c|}{ Flavonouds } & \\
\hline Aluminium chloride Test & $\begin{array}{l}2 \mathrm{~mL} \text { extract }+5 \mathrm{~mL} 10 \% \text { sodium acetate }+3 \mathrm{~mL} 2.5 \% \\
\text { aluminium chloride }\end{array}$ & Yellow coloration & \\
\hline The Shibata Test & $\begin{array}{l}3 \mathrm{~mL} \text { extract evaporated }+2 \mathrm{~mL} 50 \% \text { methanol+2- } \\
3 \text { pieces magnesium span }+10 \text { drops concentrated } \\
\text { hydrochloric acid }\end{array}$ & $\begin{array}{l}\text { Red coloration - flavonols } \\
\text { Orange coloration - flavones }\end{array}$ & \\
\hline
\end{tabular}
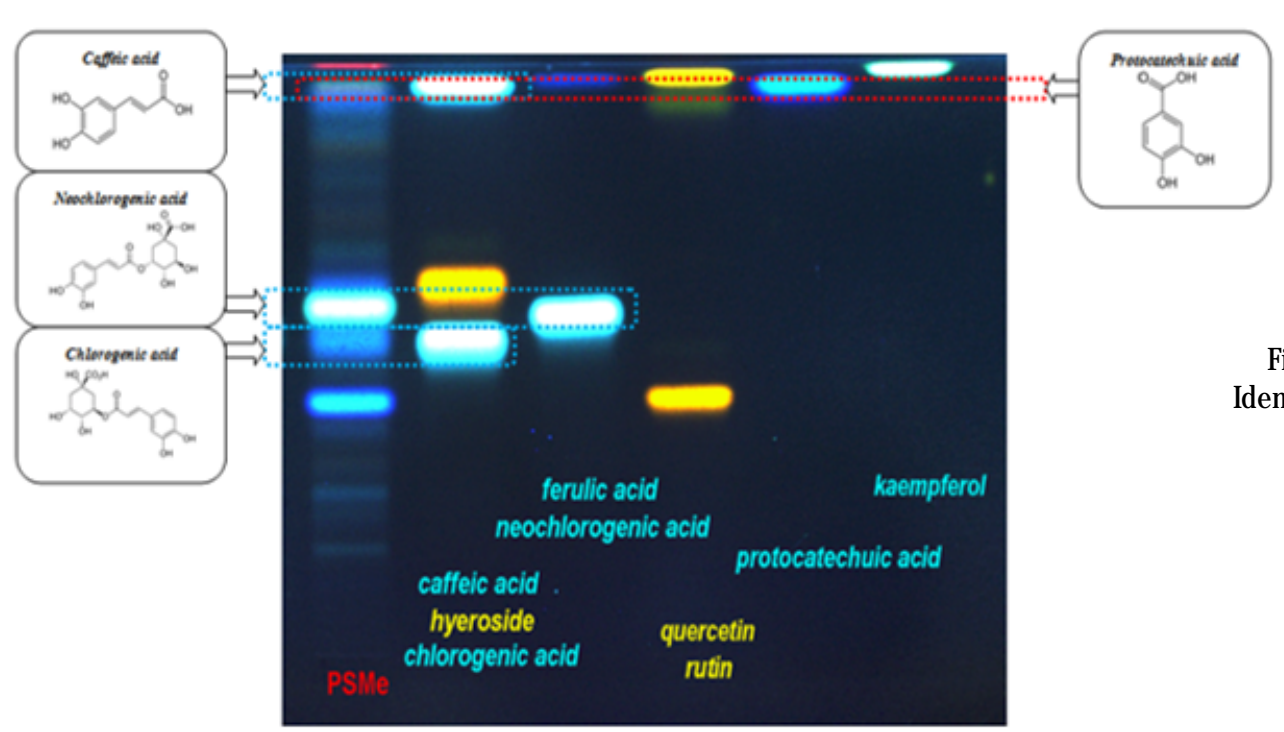

Fig.1. Polyphenols and Flavonoids Identification Chromatogram by HPTLC 
Table 2

$R$ V VALUES OF PHYTOCHEMICALS IN P. SPINOSA METHANOLIC EXTRACT (PSME)

\begin{tabular}{|c|c|c|c|c|}
\hline \multirow{2}{*}{$\begin{array}{c}\text { Image of } \\
\text { HPTLC plate }\end{array}$} & \multirow[t]{2}{*}{ Rf value } & \multirow[t]{2}{*}{ Reference standard } & \multicolumn{2}{|c|}{ Spot colour } \\
\hline & & & Reference standard & P. spinosa extract (PSMe) \\
\hline \multirow{9}{*}{$\begin{array}{c}\text { after } \\
\text { derivatization }\end{array}$} & 0.43 & Rutin & Yellow band & - \\
\hline & 0.52 & Chlorogenic acid & Blue fluorescent band & Blue fluorescent band (diffuse) \\
\hline & 0.58 & Neochlorogenic acid & Blue fluorescent band & Blue fluorescent band (intense) \\
\hline & 0.62 & hyperoside & Yellow band & - \\
\hline & 0.95 & Caffeic acid & Blue fluorescent band & $\begin{array}{c}\text { Bhue fluorescent band (low } \\
\text { intensity) }\end{array}$ \\
\hline & 0.96 & Protocatechuic acid & Blue fluorescent band & $\begin{array}{l}\text { Bhe fluorescent band (low } \\
\text { intensity) }\end{array}$ \\
\hline & 0.97 & Ferulic acid & Blue band & - \\
\hline & 0.97 & Quercetin & Yellow band & - \\
\hline & 0.98 & Kaempherol & Blue fluorescent band & - \\
\hline
\end{tabular}

using CAMAG Reprostar 3 with digital video camera, on derivatized plate at $366 \mathrm{~nm}$ (Fig. 1). The $R f$ values of phytochemicals in P. spinosa extract (PSMe) are presented in table 2. The corresponding digital scanning profiling (Fig. 2) was carried out with a Camag TLC Scanner III fitted with WinCATS software (Camag, Switerland), used for the densitometric measurements, spectra recording and data processing. Densitograms were recorded at the 254 $\mathrm{nm}$ wavelength for polyphenols (neochlorogenic acid). The analysis were performed in air-conditioned room maintained at $22^{\circ} \mathrm{C}$.

The densitometric evaluation of neochlorogenic acid spot in sample (PSMe) was carried out using a Camag TLC
Scanner III. The scanner was combined with WinCATS software for the evaluation of densitometry results. Scan settings: slit dimension $12 \times 0.4 \mathrm{~mm}$, scanning speed 20 $\mathrm{mm} / \mathrm{s}$, data resolution $100 \mu \mathrm{m} / \mathrm{step}$. Spectral detection was carried out between 200 and $700 \mathrm{~nm}$ wavelengths (Fig. 3). The retention factor ( $R f)$ was calculated by the WinCats software. The percentage of neochlorogenic acid present in methanolic extracts of $P$. spinosa was calculated by comparison of the peak height measured for standard solution (Table 3).

\section{Quantitative analysis}

Determination of total phenolic content: The total phenolic concentration was determined according to Folin-

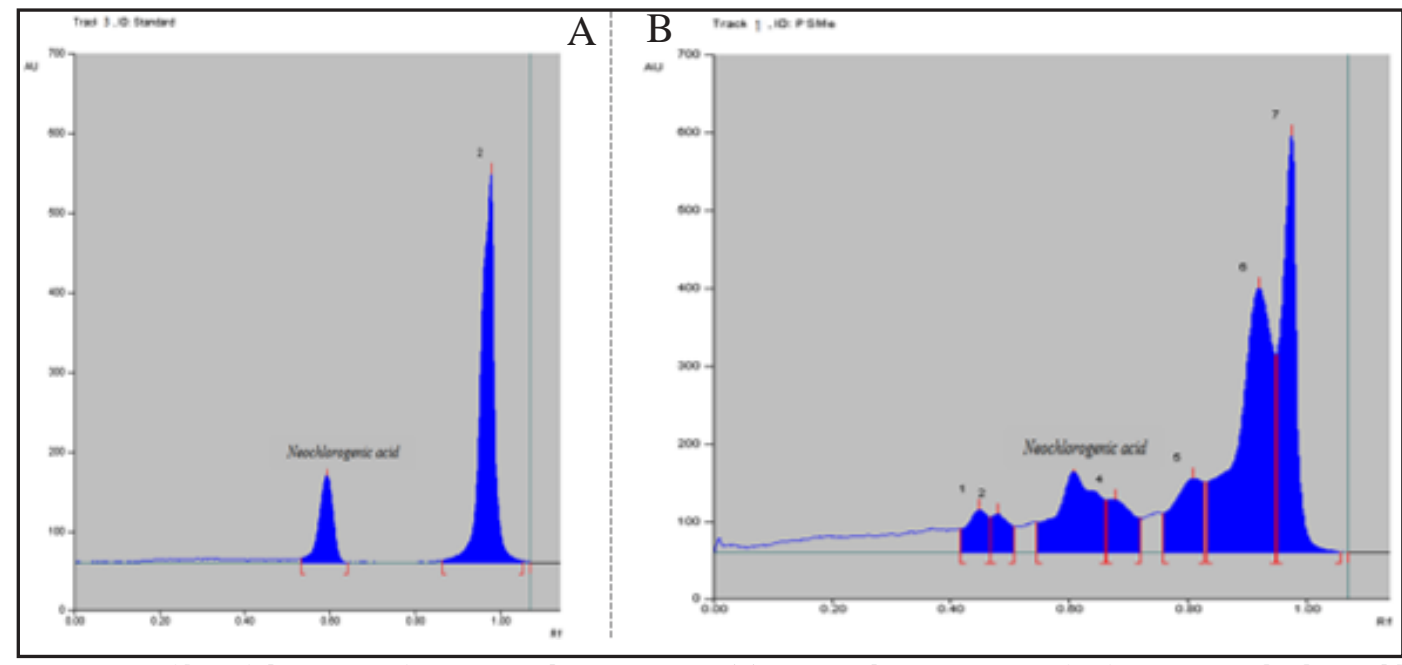

Fig. 2. Digital scanning profiles of the HPTLC fingerprint chromatogram (A)HPTLC chromatogram of reference standard neochlorogenic acid Legend: 2 - unknown polyphenol; (B)HPTLC chromatogram of P. spinosa methanolic extract (PSMe) Legend: 1, 2, 4, 5, 6, 7 - unknown polyphenols

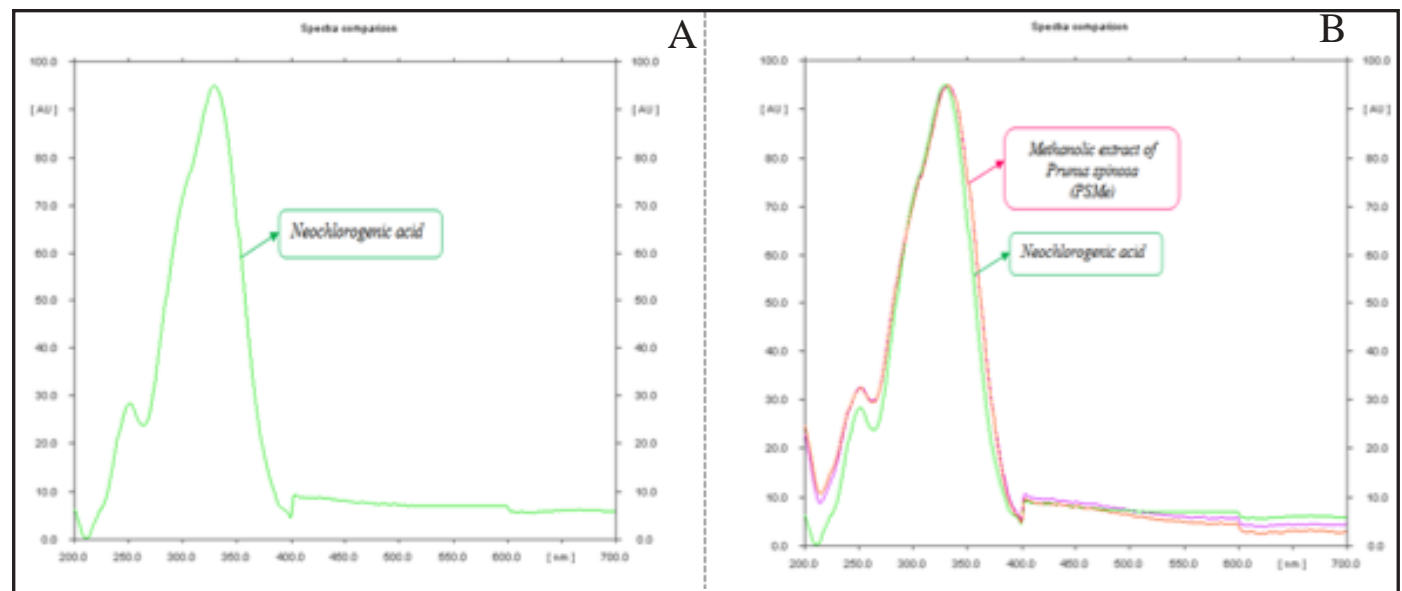

Fig. 3. Spectra of neochlorogenic acid in reference standard and $P$. spinosa methanolic extract (PSMe)(A)UV spectra of neochlorogenic acid as reference; (B) Spectral comparison of methanolic extract P. spinosa (PSMe) with reference standard neochlorogenic acid 
Table 3

THE RESULTS OF DENSITOMETRIC DETERMINATION OF NEOCHLOROGENIC ACID IN P. SPINOSA METHANOLIC EXTRACT (PSME)

\begin{tabular}{|c|c|c|c|c|}
\hline Sample & $\begin{array}{c}\text { Applied } \\
\text { volume } \\
\mu \mathrm{L}\end{array}$ & $\begin{array}{c}\text { Calculated quantity } \\
\text { based on peak height, } \\
\mathrm{ng}\end{array}$ & $\begin{array}{c}\text { Quantity of the compound } \\
\text { in methanolic extract, } \\
\mathrm{mg} / 100 \mathrm{ml}\end{array}$ & $\begin{array}{c}\text { Concentration } \\
\text { (Neochlorogenic acid) } \\
\text { (\%) }\end{array}$ \\
\hline $\begin{array}{c}\text { Reference } \\
\text { standard solution } \\
\text { (neochlorogenic } \\
\text { acid) }\end{array}$ & 4 & - & - & in dried vegetal material \\
\hline PSMe & 13 & 758.65 & 5.8 & \\
\hline
\end{tabular}

Ciocalteu procedure [11], using Folin-Ciocalteu reagent. The same procedure was performed for the gallic acid standard curve. The results were expressed in mg of gallic acid equivalent (GAE) per gram of dried vegetal material (\% g GAE/g) taking into account the sample dilution. The analyses were performed in triplicates.

Determination of total tannins content: The total tannins compound was determined according to Folin-Denis method [12], using Folin-Denis reagent. The absorbance was measured at $726 \mathrm{~nm}$ using a spectrophotometer (UVVis CARY50). A standard calibration curve was obtained for the tannic acid following the same procedure. The results were expressed in grams of tannic acid equivalent per gram of dried vegetal material $(\% \mathrm{~g} / \mathrm{g})$, taking into account the sample dilution. The analyses were performed in triplicates.

\section{Results and discussions}

The chemical composition of branches of $P$. spinosa was less studied and this is the reason why the following chemical and instrumental methods of identification were used in order to confirm the presence of interesting polyphenolic compounds.

Qualitative analysis: The results of phytochemical study are presented in table 4 . These results revealed that the various alcoholic and aqueous extracts of branches of $P$. spinosa contain polyphenols, tannins and flavonoids. The phenols, tannins and flavonoids were detected in all type of extracts obtained from the vegetal species, with high, moderate and low intensity.

Phenolic compounds were detected in all type of extracts, with high and moderate intensity. The ferric chloride test showed a dark-green coloration, which has indicated the tannins presence in all extracts, with high intensity in those obtained with $70 \%$ ethanol. Flavonoids were detected in all type of extracts, with moderate content in methanolic extract. Thus, $50 \% \mathrm{v} / \mathrm{v}$ and $70 \% \mathrm{v} / \mathrm{V}$ ethanol were the most efficient extraction solvents.

UV-VIS analysis of phenolic compounds was performed on methanol extract (PSMe) and the spectra is presented in figure 4. Depending on the specific absorption, flavonoids were identified at wavelength between 250-260 nm and condensed tannins in the range of $270-290 \mathrm{~nm}$. The results proved that methanolic extract showed maximum absorption peaks for flavonoids such as rutin and quercetin at $255 \mathrm{~nm}$ and for condensed tannins such as catechin at $280 \mathrm{~nm}$.

In the FT-IR spectra (Fig. 5) for the powdered vegetal material ( $P$. spinosa - branches) there are some wavelengths which can be attributed to $\mathrm{OH}$ group at 3279 $\mathrm{cm}^{-1}$ and to $\mathrm{C}-\mathrm{H}$ strech at $2903 \mathrm{~cm}^{-1}$. Specific absorption bands corresponding to stretching vibrations of the $\mathrm{C}-\mathrm{C}$

Table 4

QUALITATIVE PHYTOCHEMICAL ANALYSIS OF VARIOUS ALCOHOLIC AND AQUEOUS EXTRACTS OF P. SPINOSA BRANCHES.

\begin{tabular}{|c|c|c|c|c|c|c|}
\hline \multirow{2}{*}{\multicolumn{2}{|c|}{ Plant constituents/Solvents }} & \multirow{2}{*}{\multicolumn{5}{|c|}{ Prunus spinosa branches (PS) }} \\
\hline & & & & & & \\
\hline \multirow{3}{*}{$\begin{array}{l}\text { Phenolic } \\
\text { compounds }\end{array}$} & $\begin{array}{l}\text { The Folin- } \\
\text { Ciocalteu test }\end{array}$ & ++ & ++ & +++ & ++ & ++ \\
\hline & $\begin{array}{l}\text { The ferric } \\
\text { chloride test }\end{array}$ & ++ & + & +++ & +++ & ++ \\
\hline & Arnow test & ++ & ++ & +++ & +++ & +++ \\
\hline Tannins & $\begin{array}{l}\text { The ferric } \\
\text { chloride test }\end{array}$ & ++ & + & +++ & ++ & + \\
\hline \multirow[t]{2}{*}{ Flavonoids } & $\begin{array}{l}\text { The aluminium } \\
\text { chloride test }\end{array}$ & ++ & + & + & + & + \\
\hline & The Shibata test & + & + & + & ++ & ++ \\
\hline
\end{tabular}

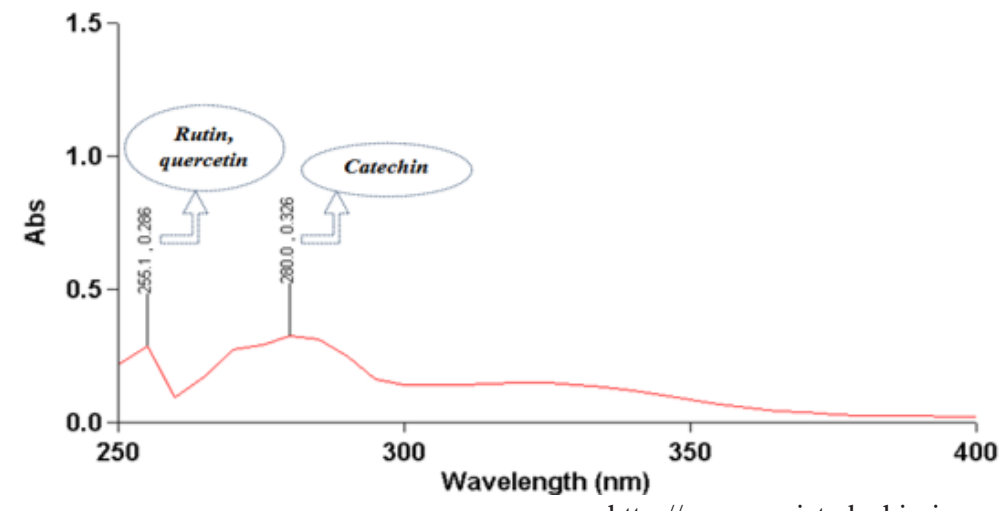

Fig. 4. UV-Vis absorption spectra of $P$. spinosa methanolic extract (PSMe) 


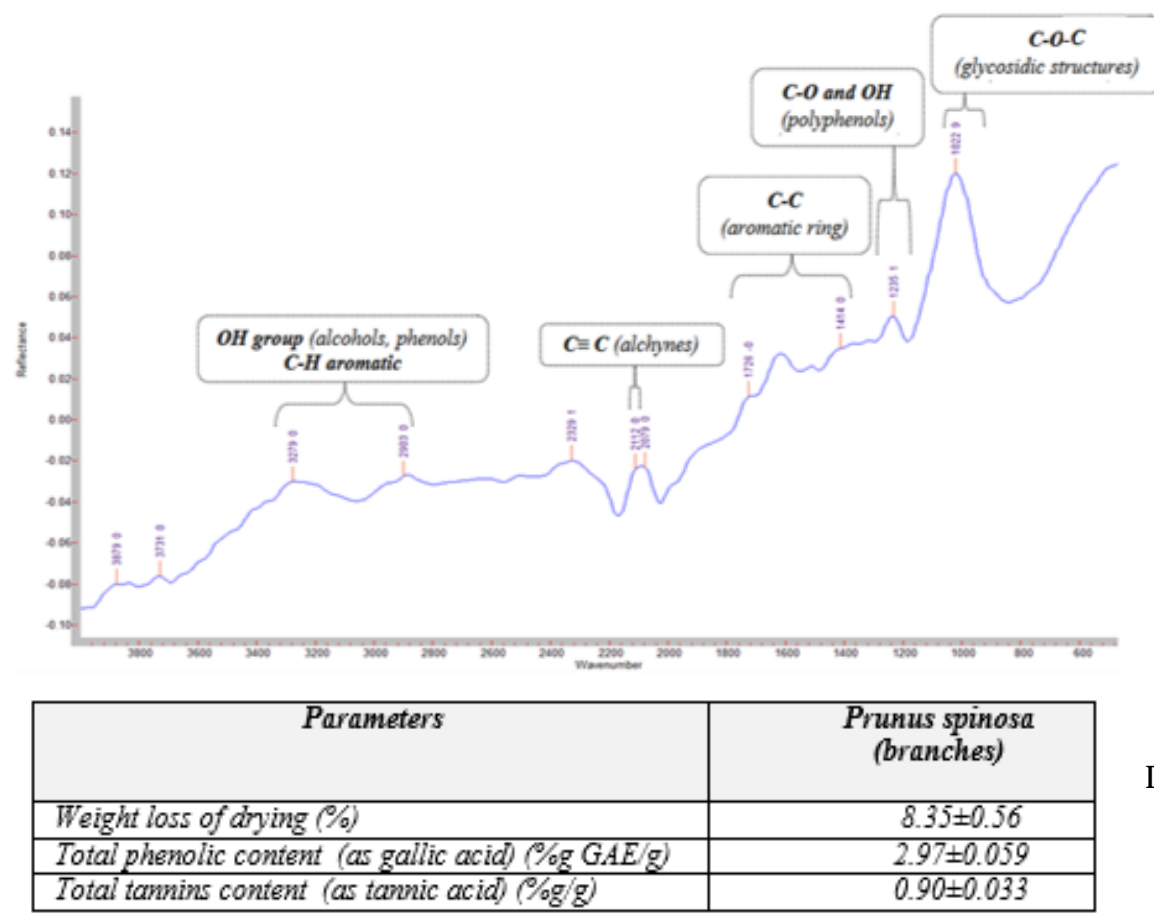

Fig. 5. FT-IR spectra of pow dered vegetal material (branches) of $P$. spinosa

(aromatic ring) can be observed at $1726 \mathrm{~cm}^{-1}$ and 1414 $\mathrm{cm}^{-1}$. Peaks at $1235 \mathrm{~cm}^{-1}$ can be assigned to $\mathrm{C}-0$ and $\mathrm{OH}$ groups from polyphenols and at $1022 \mathrm{~cm}^{-1}$ corresponding to $\mathrm{C}-\mathrm{O}$ bond from glycosidic structures. FT-IR spectra of pow dered vegetal material (branches) of Prunus spinosa is presented in figure 5 .

Interpretation of HPTLC fingerprint chromatogram: The extract from $P$. spinosa (PSMe) was analysed by HPTLC according to the methods described in the experimental section. Methanolic extract was scanned under UV at 254 $\mathrm{nm}$ and $366 \mathrm{~nm}$. The presence of polyphenols was detected as distinct blue fluorescent bands and the presence of flavonoids was visualised as distinct yellow bands. The HPTLC image (Fig. 1) indicates that the sample constituents were clearly separated. Blue fluorescent bands corresponding to chlorogenic acid ( $R f 0.52)$, neochlorogenic acid ( $R f 0.58)$, caffeic acid ( $R f 0.95$ ) and protocatechuic acid ( $R f 0.96)$ were identified in methanolic extract (track 1 - PSMe), under specific chromatographic conditions and after derivatization at $366 \mathrm{~nm}$.

Interpretation of digital scanning profiles of the HPTLC fingerprint chromatogram: The peak intensity of neochlorogenic acid was in accordance with those of blue fluorescent band. According to this, the neochlorogenic content in sample can be evaluated by quantitative comparison of peak intensity (maximum peak heights).

Figure 2 presents the digital scanning profile of $P$. spinosa methanolic extract (PSMe) at $254 \mathrm{~nm}$. Neochlorogenic acid (at $R f$ 0.58) fraction in extract track is represented as a specific peak with defined value of absorbance and height. The absorption spectra of the reference standard neochlorogenic acid overlaps the spectra of neochlorogenic acid separated from the vegetal material P. spinosa branches (fig. 3B).

Densitometric analysis: The screening at $254 \mathrm{~nm}$ has as result the quantitative determination of the phytocompound neochlorogenic acid in the $P$. spinosa methanolic extract. The calculated quantity of neochlorogenic acid in reference standard solution and extract was done based on the peak hight using the WinCats software. The HPTLC densitometry analysis revealed the amount of neochlorogenic acid in extracts from branches of $P$. spinosa as $0.12 \% \mathrm{~g} / \mathrm{g}$ reported at dried vegetal material (fig 2, table 3). The HPTLC profile and the recorded $R f$ values could serve for the scientists in the research activity developed in the field of medicinal plants.

Quantitative analysis: In this work, the total polyphenolic content in branches of $P$. spinosa was established. The vegetal material (branches) has $8.35 \%$ weight loss of drying. The obtained results showed a content in polyphenols (2.97 $\pm 0.059 \% \mathrm{~g}$ gallic acid equivalent $/ \mathrm{g})$ and tannins $(0.90 \pm 0.033 \% \mathrm{~g}$ tannic acid equivalent $/ g)$ (table 5).

\section{Conclusions}

This study presents the results of investigating polyphenols and flavonoids separated from $P$. spinosa branches using different extraction solvents and applying various qualitative and quantitative methods. Phenols, flavonoids and tannins were evidenced using specific phytochemical tests. The flavonoids such as rutin and quercetin (maximum absorption peak at $255 \mathrm{~nm}$ ) and condensed tannins such as catechin (maximum absorption peak at 280nm) were detected using UV-VIS spectroscopy. Intense absorption bands corresponding to stretching vibration of functional groups specific to polyphenols and flavonoids (OH group $3279 \mathrm{~cm}^{-1}, \mathrm{C}-\mathrm{H}$ aromatic $2903 \mathrm{~cm}^{-1}$, C-C from aromatic ring $1726 \mathrm{~cm}^{-1}, \mathrm{C}$ $\mathrm{O}$ and $\mathrm{OH}$ group from polyphenols $1235 \mathrm{~cm}^{-1}$ ) were detected using FT-IR spectroscopy. UV-VIS and FT-IR spectroscopy were applied to complete the qualitative confirmation of polyphenolic and flavonoidic compounds in branches of $P$. spinosa. Phytocompounds such as chlorogenic acid ( $R f 0.52$ ), neochlorogenic acid ( $R f 0.58$ ), caffeic acid ( $R f 0.95$ ) and protocatechuic acid ( $R f 0.96$ ) were HPTLC fingerprinted from crude methanol extract. The quantitative analysis revealed the branches of $P$. spinosa contain polyphenols $(2.97 \pm 0.059 \%$ gallic acid equivalent $/ \mathrm{g}$ dried vegetal material), tannins $(0.90 \pm 0.033 \% \mathrm{~g}$ tannic acid equivalent $/ \mathrm{g}$ dried vegetal material) and neochlorogenic acid $0.12 \% \mathrm{~g} / \mathrm{g}$ dried vegetal material(determined by HPTLC densitometry). The obtained results revealed that $P$. spinosa species is an important source of biomass, rich in polyphenols and flavonoids, which can be exploited in order to obtain phytocompounds with biological activity. 


\section{References}

1.BUJOR, O.C., LE BOURVELLEC, C., VOLF, I., POPA, V.I., DUFOUR, C., Food chem., 213, 2016, p. 58-68.

2.VOLF, I., POPA, V.I., Vitis, 2004, p. 707-710.

3.OLSZEWSKA, M., AND WOLBI'S, M., Acta Pol. Pharm., 59, 2002a, p. 133-137.

4.PINACHO, R, CAVERO, R.Y., ASTIASARAN, I., ANSORENA, D., CALVO, M.I., J Funct Foods, 19, 2015; p. 49-62.

5.BARROS, L., CARVALHO, A. M., MORAIS, J. S., FERREIRA, I. C. F. R., Food Chem., 120, 2010, p. 247-254, doi: 10.1016/j.foodchem.2009.10.016 6. IGNAT, I., VOLF, I., POPA, V.I., Food chem.., 126 (6), 2011, p. 1821 1835.

7.CIULEI, I., GRIGORESCU, E., STANESCU, U., Plante medicinale, fitochimie oi fitoterapie - tratat de farmacognozie, I. Edit. Medicala, Bucuresti, 1993, p. 226-237
8.dhARmender, R., MAdHAVI, T., ReEnA, A., SheetAl., A., Pharm. Anal. Acta., 1, 2010, p. 1-9.

9.TEBRENCU, C.E., CRETU, R.M., MITROI, G.R., IACOB, E., IONESCU, I., Phytochem. Rev, 2015; DOI 10.1007/s11101-015-9410-8.

10.STEFANACHE, C.P., PETER, S., MEIER, B., DANILA, D., TANASE, C., WOLFRAM, E., Rev. Chim. (Bucharest), 66, no. 5, 2015, p. 784-787. 11.SINGLETON, V.L, ROSSI, J., Am J Enol Viticult, 16, 1965, p. 144-158. 12.KATOCH, R., Analytical techniques in biochemistry and molecular biology, Springer, 2011, p. 301-303.

Manuscript received: 17.07 .2017 